\title{
Erratum to: Dysfunction of the Lower Esophageal Sphincter and Dysmotility of the Tubular Esophagus in Morbidly Obese Patients
}

M. A. Küper • K. M. Kramer • A. Kirschniak •

M. Zdichavsky • J. H. Schneider • D. Stüker • T. Kratt •

A. Königsrainer • F. A. Granderath

Published online: 12 February 2010

(C) Springer Science+Business Media, LLC 2010

Erratum to: OBES SURG

DOI 10.1007/s11695-009-9881-z

The surname of the third author was misspelled in the original publication. The correct spelling is A. Kirschniak.

The online version of the original article can be found under at http://dx.doi.org/10.1007/s11695-009-9881-z.

M. A. Küper $(\varangle) \cdot$ K. M. Kramer $\cdot$ M. Zdichavsky $\cdot$

J. H. Schneider · D. Stüker · T. Kratt · A. Königsrainer

Department of General, Visceral, and Transplant Surgery,

University of Tübingen,

Hoppe-Seyler-Straße 3,

72076 Tübingen, Germany

e-mail: Markus.kueper@med.uni-tuebingen.de

\section{A. Kirschniak · F. A. Granderath}

Department of General, Visceral and Minimally Invasive Surgery,

Hospital Neuwerk,

Mönchengladbach, Germany 